\title{
Idiopathic Primary Hypoparathyroidism Presenting as Focal Seizures in a Neonate: A Rare Occurrence
}

\author{
Talal Almas ${ }^{1}$, Irfan Ullah 2, 3, 4 , Mehwish Kaneez ${ }^{5}$, Maryam Ehtesham ${ }^{1}$, Shahzad Rauf 6 \\ 1. Internal Medicine, Royal College of Surgeons in Ireland, Dublin, IRL 2. Researcher, Undergraduate Research \\ Organisation, Dhaka, BGD 3. Internal Medicine, Kabir Medical College, Peshawar, PAK 4. Internal Medicine, Naseer \\ Teaching Hospital, Peshawar, PAK 5. Internal Medicine, Rawalpindi Medical University, Rawalpindi, PAK 6. Pediatrics, \\ Khyber Teaching Hospital, Peshawar, PAK
}

Corresponding author: Shahzad Rauf, rauf_shahzad@yahoo.com

\begin{abstract}
Focal seizures in neonates presenting to the emergency department can be potentially dangerous and lifethreatening. Hypoparathyroidism is an exceedingly rare but treatable cause of focal neonatal seizures. Due to its weak association with neonatal seizures, hypoparathyroidism often remains undetected as a potential cause. We hereby elucidate a rare case of idiopathic hypoparathyroidism presenting as right-sided focal seizures in a 12-day-old female neonate with an uneventful birth history. Despite the administration of antibiotics and phenobarbitone, the seizures remained unabated. Laboratory workup revealed the diagnosis of late-onset hypocalcemia with severe hypoparathyroidism. The patient was subsequently treated with calcium supplements and alfacalcidol. Thereafter, the frequency of seizures gradually decreased and the same treatment regimen was continued until the patient was seizure-free. The patient continues to do well to date with complete remission of his clinical symptoms.
\end{abstract}

Categories: Endocrinology/Diabetes/Metabolism, Internal Medicine, Pediatrics

Keywords: neonatal hypoparathyroidism, focal seizures, hypocalcemia

\section{Introduction}

Neonatal seizures, which are a frequently encountered medical emergency, can arise due to a multitude of clinical conditions [1]. Timely assessment and treatment of the etiology underlying neonatal seizures are pivotal [2]. Failure to detect the underlying cause of neonatal seizures can lead to adverse outcomes, including cognitive impairment, potentially culminating in death [1-2]. The presence of focal seizures in a neonate can be a sign of worsening meningitis, sepsis, cerebral ischemia, inherent metabolic errors, or electrolyte imbalance. Nevertheless, the presentation of endocrinological disorders in neonates as focal seizures is exceedingly rare [3-4]. We hereby delineate an interesting case of a 12-day-old female neonate who presented with right-sided focal fits. Initial laboratory workup revealed hypocalcemia, with all other

Received 08/31/2020

Review began 09/03/2020 Review ended 09/04/2020 Published 09/10/2020

๑) Copyright 2020

Almas et al. This is an open access article distributed under the terms of the Creative Commons Attribution License CC-BY 4.0., which permits unrestricted use, distribution, and reproduction in any medium, provided the original author and source are credited. electrolytes in their normal ranges. Further diagnostic workup revealed low levels of parathyroid hormone, thereby unmasking a diagnosis of idiopathic primary hypoparathyroidism presenting as late-onset hypocalcemic fits.

\section{Case Presentation}

A 12-day-old, full-term female baby, previously normal, was brought to the emergency department with right-sided focal fits. The baby was the product of a consanguineous marriage. However, consanguineous marriage might not be a cause of the patient's symptoms. The antenatal and birth histories of the baby were uneventful. Pertinently, the mother had no prior history of diabetes, hyperparathyroidism, hyperlipidemia, epilepsy, or any other endocrinological or metabolic disturbances during pregnancy that might be a cause of the baby's focal seizures. On arrival, the patient was vitally stable, active, and demonstrated no signs of dysmorphism. The occipitofrontal circumference (OFC) was $36 \mathrm{~cm}$, the anterior fontanelle was normal, and the suckling reflex was intact. Physical examination revealed unremarkable hips, back, and genitalia. The lungs were clear on auscultation, with no audible murmur and no visceromegaly on abdominal examination. Thereafter, the patient was admitted to the special neonatal unit. Despite the administration of empirical intravenous antibiotics (cefotaxime and gentamicin), the patient continued to have right-sided focal fits for which she was given phenobarbitone. There was mild clinical improvement after phenobarbitone administration but the seizures remained unabated.

The laboratory investigations revealed hypocalcemia with hypoparathyroidism. Since low levels of parathyroid hormone are intricately linked with an increased incidence of hypocalcemia and increased seizure frequency, it was established as a cause of the patient's focal fits. Table 1 elucidates the patient's laboratory findings with their normal ranges. 


\section{Cureus}

\begin{tabular}{|c|c|c|}
\hline Investigations & Results & Normal values \\
\hline Hemoglobin & $15 \mathrm{~g} / \mathrm{dL}$ & $13.4-19.9 \mathrm{~g} / \mathrm{dL}$ \\
\hline Total lymphocyte count & 10,000/microlitre & 4000-11,000/microliter. \\
\hline Platelet count & 368,000/microlitre & $150,000-450,000 /$ microliter \\
\hline C-reactive protein & Normal & $<7 \mathrm{mg} / \mathrm{L}$ \\
\hline Total serum calcium & $5.5 \mathrm{mg} / \mathrm{dL}$ & $8.4-10.6 \mathrm{mg} / \mathrm{dL}$ \\
\hline Parathyroid hormone & $<1.2 \mathrm{pg} / \mathrm{mL}$ & $14-67 \mathrm{pg} / \mathrm{ml}$ \\
\hline Serum phosphorus & $8.2 \mathrm{mg} / \mathrm{dL}$ & $4.2-9.0 \mathrm{mg} / \mathrm{dl}$ \\
\hline Serum magnesium & $2.5 \mathrm{mg} / \mathrm{dL}$ & 1.7 to $2.4 \mathrm{mg} / \mathrm{dL}$ \\
\hline Alkaline phosphatase & $429 \mathrm{U} / \mathrm{L}$ & 48-406 U/L \\
\hline
\end{tabular}

TABLE 1: The patient's laboratory workup results

To further evaluate the cause of the patient's hypoparathyroidism, a contrast-enhanced computed tomography (CT) scan of the head, neck, and chest was performed that revealed no abnormalities, with no evidence of Di-George syndrome. The laboratory workup alluded to the patient's underlying hypoparathyroidism as a potential cause of the patient's hypocalcemic fits. Notably, most cases of hypoparathyroidism in neonates are due to maternal hyperparathyroidism, which suppresses the fetal parathyroid hormone levels and thus causes seizures [3-4]. Interestingly, the gestational maternal parathyroid hormone levels were in normal ranges (31-37 pg/ml during the pregnancy), yielding the diagnosis of idiopathic primary neonatal hypoparathyroidism. Therefore, all other causes of hypoparathyroidism such as Di-George syndrome, maternal hyperparathyroidism, and hypomagnesemia, were ruled out in our patient. Alfacalcidol, calcium carbonate, and calcium gluconate were thus added to the treatment regimen in order to correct the hypocalcemia and decrease the frequency of seizures in the patient. Thereafter, the frequency of the fits gradually decreased and the patient's clinical symptoms abated.

\section{Discussion}

Hypocalcemia consequent to low levels of circulating parathyroid hormone is the hallmark of hypoparathyroidism [5]. Hypoparathyroidism due to non-surgical causes, such as Di-George syndrome, idiopathic, or autoimmune destruction of parathyroid glands, is an exceedingly rare entity with a prevalence hovering around two to three per 100,000 adults; however, its prevalence in neonates is even lower, with only scarce data available [6]. The previously published literature espouses the notion that neonates with idiopathic primary hypoparathyroidism present with low levels of circulating calcium that might, in turn, lead to the development of seizures [3-4]. In our case, the etiology was suspected to be of an infectious nature on presentation, but the laboratory findings suggested otherwise. Intravenous infusion of cefotaxime and gentamicin was thus commenced; however, the frequency of the seizures remained unaltered. As a result, phenobarbitone was administered, owing to its anti-seizure activity, which subsequently resulted in clinical improvement.

Hypocalcemia in neonates is described as total serum calcium levels of less than $7 \mathrm{mg} / \mathrm{dL}$ [7]. Our patient presented to us with late-onset hypocalcemia, which is defined as hypocalcemia occurring after the first week of life. The causes of late-onset neonatal hypocalcemia include low levels of vitamin D, maternal hyperparathyroidism, hypomagnesemia, and primary hypoparathyroidism [8]. In our patient, the serum magnesium levels were in their normal ranges, and maternal hyperparathyroidism was ruled out as a likely cause of hypocalcemia. On further workup, the patient had very low levels of parathyroid hormone that caused low levels of serum calcium and high levels of serum phosphate that ultimately led to right-sided focal fits. The possibility of Di-George syndrome was ruled out as the patient had an intact parathyroid and thymus as visualized on the CT scan. To address the symptomatic hypocalcemia and increasing focal fits, treatment with alfacalcidol and calcium carbonate was initiated. Hussain S et al. also reported a similar case that presented with focal seizures and late-onset hypocalcemia due to hypoparathyroidism. Pertinently, their patient was treated with oral calcium supplements and cholecalciferol after which the seizures halted, and a six-month follow-up showed no complications [3]. Another study reported the successful treatment of a 28-day neonate by employing a similar therapeutic regimen [4]. The decision to initiate our treatment protocol was, therefore, based on evidence from these two cases [3-4]. In most instances, congenital hypoparathyroidism is linked with Di-George syndrome [9]. In our patient, however, Di-George syndrome was ruled out, as the CT showed a mediastinal window with an intact thymus and normal parathyroid glands in the neck. 


\section{Cureus}

Our case, therefore, highlights that prompt diagnosis of this idiopathic condition and appropriate management with calcium and vitamin D can help in preventing complications and mortality in neonates [3-4]. In order to better understand our case, we queried several databases. The results of our literature search are tabulated in Table 2 .

\begin{tabular}{|c|c|c|}
\hline Case number & Case 1 & Case 2 \\
\hline Authors & Hussain $\mathrm{S}$ et al. & LK $P$ et al. \\
\hline Age (days) & 18 days & 28 days \\
\hline Sex & Male & Male \\
\hline Calcium levels (mg/dL) & $6.01 \mathrm{mg} / \mathrm{dL}$ & $6.50 \mathrm{mg} / \mathrm{dL}$ \\
\hline $\begin{array}{l}\text { Parathyroid hormone } \\
\text { levels }\end{array}$ & $9.0 \mathrm{pg} / \mathrm{ml}$ & $1.0 \mathrm{pg} / \mathrm{ml}$ \\
\hline Birth history & Uneventful & Uneventful \\
\hline Type of seizures & Focal & Generalized \\
\hline Treatment given & Oral calcium supplement + Cholecalciferol & Calcium and Vitamin D3 supplements \\
\hline Follow-up & $\begin{array}{l}\text { Upon 6-month follow-up, the patient is seizure-free with no signs of } \\
\text { nephrocalcinosis. }\end{array}$ & $\begin{array}{l}\text { Upon 1-month follow up, the neonate is } \\
\text { seizure-free. }\end{array}$ \\
\hline Reference number & 3 & 4 \\
\hline
\end{tabular}

TABLE 2: Previously documented cases of idiopathic primary hypoparathyroidism presenting as neonatal seizures

\section{Conclusions}

Idiopathic primary hypoparathyroidism can rarely present as focal seizures in neonates that can be successfully treated with previously reported pharmaceutical regimens. These regimens typically consist of calcium and vitamin D3 supplements. However, the data pertaining to the utility and efficacy of such regimens remains strictly anecdotal. There is thus an unmet need for appropriate treatment guidelines to be curated for the management of similar cases in order to avoid complications and patient mortality.

\section{Additional Information}

\section{Disclosures}

Human subjects: Consent was obtained by all participants in this study. Conflicts of interest: In compliance with the ICMJE uniform disclosure form, all authors declare the following: Payment/services info: All authors have declared that no financial support was received from any organization for the submitted work. Financial relationships: All authors have declared that they have no financial relationships at present or within the previous three years with any organizations that might have an interest in the submitted work. Other relationships: All authors have declared that there are no other relationships or activities that could appear to have influenced the submitted work.

\section{References}

1. Baudou E, Cances C, Dimeglio C, Lecamus CH: Etiology of neonatal seizures and maintenance therapy use: a 10-year retrospective study at Toulouse Children's hospital. BMC Pediatr. 2019, 19:136. 10.1186/s12887019-1508-5

2. Heljic S, Uzicanin S, Catibusic F, Zubcevic S: Predictors of mortality in neonates with seizures; a prospective cohort study. Med Arch. 2016, 70:182-185. 10.5455/medarh.2016.70.182-185

3. Hussain S, Sabir MU, Ali M, Shah SA: Neonatal idiopathic primary hypoparathyroidism: a rare cause of neonatal seizures. Pak J Med Sci. 2015, 31:1277-1279. 10.12669/pjms.315.7807

4. LK P, Kannan PR, Shanbhag M: An unusual case of neonatal seizures as manifestation of asymptomatic maternal hypoparathyroidism. BMJ Case Rep. 2019, 12:e229160. 10.1136/bcr-2018-229160

5. Mannstadt M, Bilezikian JP, Thakker RV, et al.: Hypoparathyroidism. Nat Rev Dis Primers. 2017, 3:17055. 10.1038/nrdp.2017.55

6. Clarke BL, Brown EM, Collins MT, et al.: Epidemiology and diagnosis of hypoparathyroidism. J Clin Endocrinol Metab. 2016, 101:2284-2299. 10.1210/jc.2015-3908

7. Jain A, Agarwal R, Sankar MJ, Deorari A, Paul VK: Hypocalcemia in the newborn. Indian J Pediatr. 2010, 77:1123-1128. 10.1007/s12098-010-0176-0 


\section{Cureus}

8. Do HJ, Park JS, Seo JH, Lee ES, Park CH, Woo HO, Youn HS: Neonatal late-onset hypocalcemia: is there any relationship with maternal hypovitaminosis D?. Pediatr Gastroenterol Hepatol Nutr. 2014, 17:47-51. 10.5223/pghn.2014.17.1.47

9. Vuralli D: Clinical approach to hypocalcemia in newborn period and infancy: who should be treated? . Int J Pediatr. 2019, 2019:4318075. 10.1155/2019/4318075 